\title{
Effect of abomasal glucose infusion on plasma concentrations of gut peptides in periparturient dairy cows
}

\author{
M. Larsen, ${ }^{\star 1}$ A. E. Relling,$\dagger^{2}$ C. K. Reynolds, $\neq$ and N. B. Kristensen ${ }^{\star}$ \\ *Department of Animal Health and Bioscience, Faculty of Agricultural Sciences, Aarhus University, DK-8830 Tjele, Denmark \\ †Department of Animal Sciences, The Ohio State University, Ohio Agricultural Research and Development Center (OARDC), \\ Wooster 44691-4096 \\ ‡School of Agriculture, Policy and Development, University of Reading, Earley Gate RG6 6AR, United Kingdom
}

\begin{abstract}
Six Holstein cows fitted with ruminal cannulas and permanent indwelling catheters in the portal vein, hepatic vein, mesenteric vein, and an artery were used to study the effects of abomasal glucose infusion on splanchnic plasma concentrations of gut peptides. The experimental design was a randomized block design with repeated measurements. Cows were assigned to one of 2 treatments: control or infusion of 1,500 g of glucose/d into the abomasum from the day of parturition to $29 \mathrm{~d}$ in milk. Cows were sampled $12 \pm 6 \mathrm{~d}$ prepartum and at 4,15 , and $29 \mathrm{~d}$ in milk. Concentrations of glucose-dependent insulinotropic polypeptide, glucagon-like peptide 1(7-36) amide, and oxyntomodulin were measured in pooled samples within cow and sampling day, whereas active ghrelin was measured in samples obtained $30 \mathrm{~min}$ before and after feeding at $0800 \mathrm{~h}$. Postpartum, dry matter intake increased at a lower rate with infusion compared with the control. Arterial, portal venous, and hepatic venous plasma concentrations of the measured gut peptides were unaffected by abomasal glucose infusion. The arterial, portal venous, and hepatic venous plasma concentrations of glucose-dependent insulinotropic polypeptide and glucagon-like peptide 1(7-36) amide increased linearly from $12 \mathrm{~d}$ prepartum to $29 \mathrm{~d}$ postpartum. Plasma concentrations of oxyntomodulin were unaffected by day relative to parturition. Arterial and portal venous plasma concentrations of ghrelin were lower postfeeding compared with prefeeding concentrations. Arterial plasma concentrations of ghrelin were greatest prepartum and lowest at $4 \mathrm{~d}$ postpartum, giving a quadratic pattern of change over the transition period. Positive portal venous-arterial and hepatic venous-arterial concentration differences were observed
\end{abstract}

Received March 12, 2010.

Accepted September 12, 2010.

${ }^{1}$ Corresponding author: mogens.larsen@agrsci.dk

${ }^{2}$ Current address: National Research Council, IGEVET, CCT-La Plata, Facultad de Ciencias Veterinarias, Universidad Nacional de La Plata, Buenos Aires, Argentina. for glucagon-like peptide 1(7-36) amide. A negative portal venous-arterial concentration difference was observed for ghrelin pre-feeding. The remaining portal venous-arterial and hepatic venous-arterial concentration differences of gut peptides did not differ from zero. In conclusion, increased postruminal glucose supply to postpartum transition dairy cows reduced feed intake relative to control cows, but did not affect arterial, portal venous, or hepatic venous plasma concentrations of gut peptide hormones. Instead, gut peptide plasma concentrations increased as lactation progressed. Thus, the lower feed intake of postpartum dairy cows receiving abomasal glucose infusion was not attributable to changes in gut peptide concentrations.

Key words: dairy cow, ghrelin, glucagon-like peptide 1(7-36) amide, glucose-dependent insulinotropic polypeptide

\section{INTRODUCTION}

The transition from being a pregnant non-lactating cow to a lactating non-pregnant cow represents a great challenge for the adaptation of feed intake and glucose metabolism. Feeding diets high in ruminal escape starch to postpartum transition cows is, in theory, an attractive strategy to overcome problems with hypoglycemia and hyperlipidemia. Increased presence of carbohydrates in digesta passing to the lower digestive tract has been reported to stimulate the secretion of glucose-dependent insulinotropic polypeptide (GIP), glucagon-like peptide 1(7-36) amide (GLP-1), and oxyntomodulin (OXM) in humans (Holst, 1997, 2004) and of GIP in dairy cows (Relling and Reynolds, 2008). In nonruminants, increased glucose presence in the gastrointestinal tract has been reported to increase GIP and GLP-1 secretion (Damholt et al., 1998), and decrease ghrelin concentrations in circulating blood (Williams et al., 2003; Overduin et al., 2005). In addition, in nonruminants, GIP and GLP-1 have been reported to participate, directly and indirectly, in intake regulation and glucose metabolism (Holst, 1997, 2004). Furthermore, ghrelin has been reported to stimulate feed 
intake in both ruminants and nonruminants (Roche et al., 2008). Therefore, it could be speculated that feeding increasing amounts of ruminal escape nonstructural carbohydrates to transition cows may induce secondary effects on the adaptation of feed intake and glucose metabolism to lactation through effects on gut peptide secretion.

Gut peptide hormones are secreted into the blood circulation from endocrine cells in the gastrointestinal mucosa: GIP from duodenal K-cells, GLP-1 and OXM from jejunal L-cells (Holst, 1997, 2004), and ghrelin from gastric P/D1 cells (Inui et al., 2004). Thus, higher concentrations of gut peptides would be expected in portal venous blood compared with arterial blood. To our knowledge, portal and hepatic venous blood concentrations of GIP, OXM, and ghrelin have never been reported.

In this context, we hypothesized that abomasal glucose infusion would decrease the arterial and portal venous concentrations of ghrelin and increase concentrations of GIP, GLP-1, and OXM. The objective of this study was to investigate the effect of abomasal glucose infusion on arterial, portal vein, and hepatic vein plasma concentrations of gut peptide hormones in periparturient dairy cows.

\section{MATERIALS AND METHODS}

The present experiment complied with Danish Ministry of Justice Law No. 382 (June 10, 1987), Act No. 726 (September 9, 1993), concerning experiments with animals and care of experimental animals.

\section{Animals, Design, and Samplings}

The study was described in detail by Larsen and Kristensen (2009). In brief, 6 ruminally cannulated Danish Holstein second-lactation cows catheterized in the major splanchnic vessels were used in a randomized block design with repeated measurements. Cows were randomly assigned to 1 of 2 treatments: no infusion (control) or continuous abomasal infusion of $1,500 \mathrm{~g}$ of glucose/d from the day of parturition (infusion). Abomasal glucose infusion was conducted using a tube with flange inserted into the abomasum via the rumen cannula. A gestation diet was fed restrictedly at $10 \mathrm{~kg}$ of $\mathrm{DM} / \mathrm{d}$ in the last 3 wk prepartum. From the day of parturition, a lactation diet was fed ad libitum (10\% orts). Both diets were offered as a TMR in equally sized meals at 0800,1600 , and $2400 \mathrm{~h}$. Blood samples were collected at $12 \pm 6 \mathrm{~d}$ prepartum as well as 4,15 , and 29 DIM. Eight hourly sample sets of arterial, portal vein, and hepatic vein blood were obtained starting 30 min before feeding at $0800 \mathrm{~h}$. Blood was immediately stabilized in either heparin vacuettes (455051, Greiner BioOne $\mathrm{GmbH}$, Frickenhausen, Austria) or $\mathrm{K}_{3}$ EDTA vacuettes (455036, Greiner BioOne $\mathrm{GmbH}$ ) and placed on crushed ice. Harvested plasma was stored in polystyrene tubes at $-20^{\circ} \mathrm{C}$ until analysis. Splanchnic blood plasma flows were determined by downstream dilution of $p$-aminohippuric acid (pAH) infused $(36.4 \pm 1.3$ $\mathrm{mmol} / \mathrm{h}$ ) into a mesenteric vein. Dry matter intake and milk yield were recorded daily.

\section{Analytical Procedures}

Concentrations of pAH were determined in heparinized plasma after deacetylation by the method described by Harvey and Brothers (1962) using a continuous flow analyzer (Autoanalyzer 3, method US-216-72 Rev. 1; Seal Analytical Ltd, Burgess Hill, UK). For deacetylation of pAH, plasma was deproteinized by combining with an equal volume of $20 \%$ trichloroacetic acid (wt/ vol) and incubating the supernatant for $1 \mathrm{~h}$ at $100^{\circ} \mathrm{C}$. Heparinized plasma samples were analyzed for glucose using D-glucose oxidase (YSI 7100, YSI Inc., Yellow Springs, OH), as well as BHBA and NEFA (EDTA plasma) using enzymatic assays (RB 1008 and FA 115, respectively, Randox Laboratories Ltd., Crumlin, UK) adapted for use on a Cobas Mira autoanalyzer (Triolab A/S, Brøndby, Denmark). Plasma insulin was determined by time-resolved fluoro-immunometric assays according to Løvendahl and Purup (2002).

Gut peptide concentrations were measured in EDTAstabilized plasma. Concentrations of immunoreactive GIP, GLP-1, and OXM were measured in samples pooled within cow, sampling day, and sampling site to reduce costs, as limited variation relative to feeding time has been found previously for GIP and GLP-1 (Relling and Reynolds, 2008). Active ghrelin was measured in samples obtained $30 \mathrm{~min}$ before and after feeding at $0800 \mathrm{~h}$. The plasma concentrations of GIP and GLP-1 were determined using RIA as described by Relling and Reynolds (2007). Commercial RIA kits were used to determine OXM (OXM RIA kit RKU-028-22; Phoenix Pharmaceuticals Inc., Belmont, CA) and ghrelin (Active Ghrelin RIA kit GHRA-88HK; Linco Research, St. Charles, MO) as described by Relling et al. (2010a). The intraassay coefficients of variation were $10.3 \%$ for GIP, $6.7 \%$ for GLP-1, $11.0 \%$ for OXM, and $10.2 \%$ for ghrelin.

\section{Calculations and Statistical Procedures}

Net portal-drained visceral (PDV) and net splanchnic fluxes of gut peptides were calculated according to Kristensen et al. (2007). Data were statistically analyzed using the MIXED procedure of SAS (v. 9.2; SAS 
Institute Inc., Cary, NC). For gut peptides measured in pooled samples, the model included the fixed effect of treatment, day relative to parturition and their interaction, and the random effect of cow. Day relative to parturition within cow was considered as a repeated measure using the spatial power covariance structure, as this generally produced the lowest Akaike's information criteria score among the tested (autoregressive order 1, spatial power and Toeplitz). For ghrelin data, the model included the fixed effects of treatment, day relative to parturition, time relative to feeding, and all possible interactions, and the random effect of cow. Time relative to feeding was considered as a repeated measure using the compound symmetry covariance structure. Ghrelin concentrations were $\log _{10}$-transformed to obtain normal distribution of errors; means \pm SEM are presented. Effects of linear and quadratic orthogonal polynomial contrasts of day relative to parturition were tested. Paired $t$-tests were used to test if portal venousarterial $(\mathbf{P}-\mathbf{A})$, hepatic venous-arterial $(\mathbf{H}-\mathbf{A})$, and hepatic venous-portal venous $(\mathbf{H}-\mathbf{P})$ concentration differences differed from zero. Significance was declared at $P \leq 0.05$ and tendencies were considered at $0.05<$ $P<0.10$. Pearson correlation analysis was conducted among DMI and arterial concentrations of glucose, insulin, NEFA, BHBA, GIP, GLP-1, and OXM, as well as pre- and postfeeding ghrelin using the CORR procedure of SAS.

\section{RESULTS}

From parturition to 29 DIM, voluntary DMI increased at a lower rate $(P=0.05)$ in infusion versus control cows, and the overall treatment means were 10.7 and $16.9 \mathrm{~kg} / \mathrm{d}$, respectively. Accordingly, an interaction $(P$ $=0.04$ ) was observed between treatment and DIM for milk yield, reflecting reduced rates of increase from approximately 4 DIM in infusion versus control cows. The overall treatment means for milk yield were 19.7 and $26.7 \mathrm{~kg} / \mathrm{d}$ for infusion and control groups, respectively. The abomasal glucose infusion initiated at the day of parturition affected the arterial glucose concentration through transition $(P=0.05)$, as the glucose concentration increased slightly from prepartum to 4 DIM (3.76 to $3.92 \mathrm{mM}$ ) with infusion, but decreased (3.94 to $3.45 \mathrm{mM}$ ) with control. The absence of an immediate postpartum decrease in arterial glucose concentration with infusion was closely reflected in greater arterial concentrations of insulin $(P=0.03)$ and lower concentrations of BHBA and NEFA $(P<0.01$ and $P=0.06$, respectively; Larsen and Kristensen, 2009).

\section{Plasma Concentrations of Gut Peptides}

Arterial, portal venous, and hepatic venous plasma concentrations of the determined gut peptides seemed to be unaffected by abomasal glucose infusion $(P=$ 0.13 to $P=0.86$; Table 1 ), and further, no interactions were observed between treatments and DIM $(P=$ 0.29 to $P=0.99)$. No interaction was observed between treatment and time relative to feeding $(P=0.58$ to $P=$ 0.92; not shown) for arterial, portal venous, and hepatic venous plasma concentrations of ghrelin.

The arterial, portal venous, and hepatic venous plasma concentrations of GIP and GLP-1 increased linearly $(P<0.01$; Table 1$)$ from $12 \mathrm{~d}$ prepartum to 29 d postpartum. A tendency $(P=0.06)$ for a quadratic effect of day relative to parturition was observed for the arterial concentration of GIP. The arterial, portal venous, and hepatic venous plasma concentrations of OXM were unaffected by day relative to parturition $(P$ $=0.61$ to $P=0.73$ ).

The arterial and portal venous plasma concentrations of active ghrelin were greater $(P=0.03$ and $P<0.01$, respectively; Table 1) pre-feeding as compared with post-feeding. A quadratic polynomial effect $(P=0.04)$ of day relative to parturition on arterial ghrelin concentrations was observed, reflecting a marked decrease from prepartum to 4 DIM followed by modest increases as lactation progressed. By comparison, the portal and hepatic venous concentrations of ghrelin seemed to be unaffected ( $P=0.31$ and $P=0.63$, respectively) by day relative to parturition.

\section{Venous-Arterial Concentration Differences and Net Fluxes}

Positive $\mathrm{P}-\mathrm{A}$ and $\mathrm{H}-\mathrm{A}$ concentration differences were observed for GLP-1 $(P<0.01$ and $P=0.04$, respectively; Table 2). A negative $\mathrm{P}-\mathrm{A}$ concentration difference was observed for ghrelin prefeeding $(P=0.03)$. The remaining $\mathrm{P}-\mathrm{A}, \mathrm{H}-\mathrm{A}$, and $\mathrm{H}-\mathrm{P}$ concentration differences of gut peptides did not differ from $0(P=0.10$ to $P=0.99$ ).

The postpartum net PDV and net splanchnic release (positive net fluxes) of GLP-1 were unaffected by treatment $(P=0.56$ and $P=0.41$, respectively) and day relative to parturition $(P=0.58$ and $P=0.37$, respectively; Figure 1), and averaged $2.2 \pm 0.2$ and $2.4 \pm 1.2$ $\mathrm{nmol} / \mathrm{h}$, respectively, across the transition period.

\section{Correlations}

Of the measured gut peptides in arterial plasma, only GLP-1 indicated a positive correlation $(P=0.006$; $\mathrm{r}=0.55$; Table 3$)$ with voluntary DMI. None of the measured gut peptides in arterial plasma correlated $(P$ $\geq 0.08$ ) to arterial glucose, insulin, NEFA, or BHBA. Positive correlations were observed between arterial concentrations of GLP-1 and GIP $(P<0.0001 ; \mathrm{r}=$ $0.87)$. 
Table 1. Arterial, portal venous, and hepatic venous plasma concentrations of glucose-dependent insulinotropic polypeptide (GIP), glucagon-like peptide 1(7-36) amide (GLP-1), oxyntomodulin (OXM), and active ghrelin in periparturient cows

\begin{tabular}{|c|c|c|c|c|c|c|c|c|c|c|c|c|c|c|}
\hline \multirow[b]{2}{*}{ Item } & \multicolumn{2}{|c|}{ Treatment $^{1}$} & \multirow[b]{2}{*}{$\mathrm{SEM}^{2}$} & \multicolumn{2}{|c|}{$P$-values ${ }^{3}$} & \multicolumn{4}{|c|}{ Day relative to parturition } & \multirow[b]{2}{*}{$\mathrm{SEM}^{4}$} & \multicolumn{2}{|c|}{$P$-value ${ }^{5}$} & \multicolumn{2}{|c|}{$P$-contrast ${ }^{6}$} \\
\hline & Control & Infusion & & Trt & Trt $\times$ DIM & $-12 \pm 6$ & 4 & 15 & 29 & & Day & Time & Lin & Quad \\
\hline \multicolumn{15}{|l|}{ GIP, $\mathrm{p} M$} \\
\hline Arterial & 75 & 84 & 6 & 0.33 & 0.62 & 63 & 63 & 80 & 96 & 6 & 0.01 & - & $<0.01$ & 0.06 \\
\hline Portal venous & 73 & 83 & 3 & 0.27 & 0.63 & 64 & 61 & 80 & 94 & 7 & 0.02 & - & $<0.01$ & 0.15 \\
\hline Hepatic venous & 81 & 86 & 7 & 0.13 & 0.48 & 63 & 65 & 78 & 114 & 8 & 0.02 & - & $<0.01$ & 0.03 \\
\hline \multicolumn{15}{|l|}{ GLP-1, $\mathrm{p} M$} \\
\hline Arterial & 27 & 29 & 2 & 0.75 & 0.81 & 18 & 19 & 30 & 35 & 2 & $<0.01$ & - & $<0.01$ & 0.14 \\
\hline Portal venous & 30 & 32 & 2 & 0.46 & 0.57 & 19 & 23 & 32 & 37 & 2 & $<0.01$ & - & $<0.01$ & 0.23 \\
\hline Hepatic venous & 30 & 29 & 4 & 0.86 & 0.99 & 17 & 20 & 29 & 41 & 2 & $<0.01$ & - & $<0.01$ & 0.06 \\
\hline \multicolumn{15}{|l|}{ OXM, pM } \\
\hline Arterial & 163 & 184 & 11 & 0.40 & 0.40 & 159 & 163 & 178 & 178 & 12 & 0.61 & - & 0.23 & 0.89 \\
\hline Portal venous & 169 & 183 & 9 & 0.48 & 0.56 & 164 & 170 & 181 & 178 & 11 & 0.73 & - & 0.35 & 0.62 \\
\hline Hepatic venous & 175 & 182 & 14 & 0.66 & 0.72 & 164 & 173 & 176 & 191 & 13 & 0.69 & - & 0.34 & 0.72 \\
\hline \multicolumn{15}{|c|}{ Arterial ghrelin, $\mathrm{p} M$} \\
\hline Prefeeding & 29 & 48 & 8 & $0.33^{7}$ & 0.87 & 84 & 21 & 47 & 40 & 12 & $0.05^{7}$ & 0.03 & 0.10 & 0.04 \\
\hline Postfeeding & 21 & 34 & & & & 56 & 18 & 25 & 32 & & & & & \\
\hline \multicolumn{15}{|c|}{ Portal venous ghrelin, $\mathrm{p} M$} \\
\hline Prefeeding & 26 & 54 & 11 & $0.21^{7}$ & 0.29 & 69 & 46 & 41 & 34 & 15 & $0.31^{7}$ & $<0.01$ & 0.18 & 0.40 \\
\hline Postfeeding & 18 & 40 & & & & 50 & 29 & 32 & 27 & & & & & \\
\hline \multicolumn{15}{|c|}{ Hepatic venous ghrelin, $\mathrm{p} M$} \\
\hline Prefeeding & 33 & 60 & 16 & $0.58^{7}$ & 0.98 & 86 & 57 & 37 & 47 & 21 & $0.63^{7}$ & 0.57 & 0.34 & 0.55 \\
\hline Postfeeding & 19 & 53 & & & & 64 & 49 & 32 & 24 & & & & & \\
\hline
\end{tabular}

${ }^{1}$ Treatments (Trt) were control or continuous abomasal infusion of $1,501 \pm 25 \mathrm{~g}$ of glucose/d from 1 to 29 DIM.

${ }^{2}$ Standard error of the mean ( $\mathrm{n}=3, \mathrm{n}=2$ for hepatic venous concentrations).

${ }^{3}$ Fixed effects of treatment when prepartum observations are excluded from data set.

${ }^{4}$ Standard error of the mean ( $\mathrm{n}=6, \mathrm{n}=5$ for hepatic venous concentrations).

${ }^{5}$ Fixed effects of day relative to parturition and of time relative to feeding at $0800 \mathrm{~h}$.

${ }^{6}$ Linear and quadratic orthogonal polynomial contrasts of day relative to parturition.

${ }^{7} P$-values are for the $\log _{10}$ transformed variable; data are presented as direct means \pm SEM. 


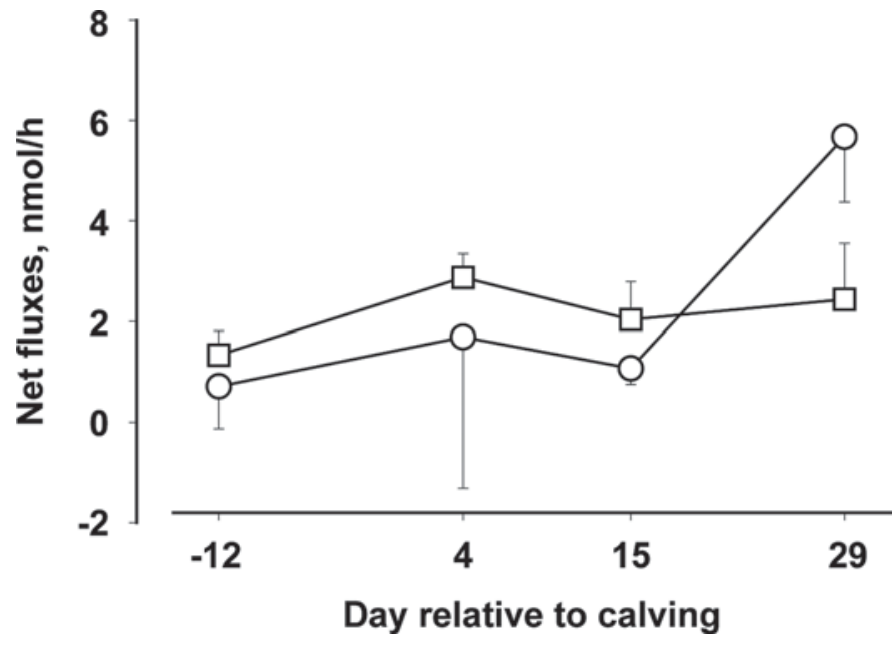

Figure 1. Net portal-drained visceral $(\square)$ and net splanchnic $(\bigcirc)$ fluxes of glucagon-like peptide 1 (GLP-1) in periparturient dairy cows. Each data point is the mean $\pm \operatorname{SEM}(\mathrm{n}=6 ; \mathrm{n}=5$ for net splanchnic flux). The net portal drained visceral and net splanchnic fluxes of GLP-1 were unaffected ( $P=0.58$ and $P=0.37$, respectively) by day relative to parturition and averaged $2.2 \pm 0.2$ and $2.4 \pm 1.2 \mathrm{nmol} / \mathrm{h}$, respectively.

\section{DISCUSSION}

The present study was undertaken to investigate whether increased glucose supply to the postruminal digestive tract of postpartum transition cows affects the adaptation of feed intake regulation and glucose metabolism to lactation through altered release of gut peptides from the splanchnic tissues. Furthermore, the profound immediate postpartum response of DMI and circulating concentrations of metabolites and insulin to the abomasal infusion of $1,500 \mathrm{~g} / \mathrm{d}$ of glucose reported previously (Larsen and Kristensen, 2009) was intriguing.

\section{Intestinal Glucose Presence}

To the authors' knowledge, the present study is the first investigating the effect of glucose supply to the abomasum on GIP, GLP-1, OXM, and ghrelin secretion in ruminants. Our observation that portal and hepatic venous plasma concentrations of GIP appeared to be unaffected by abomasal glucose infusion was unexpected, as glucose presence in the upper small intestine has been reported to stimulate GIP secretion in nonruminants (Knapper et al., 1995; Damholt et al., 1998). The potential effect of glucose infusion on GIP secretion could have been masked by differences in dietary soluble carbohydrates and other nutrients entering the small intestine due to the observed DMI difference between treatments. In lactating dairy cows, Relling and Reynolds (2008) reported an increased plasma concentration of GIP with abomasal infusion of 1,100 $\mathrm{g}$ of raw corn starch/d. The infusion of raw corn starch was probably not associated with large increases in the presence of glucose in the duodenum, due to a time lag in glucose release from the amylolytic processes and a low small intestinal digestibility of raw corn starch in dairy cows (Knowlton et al., 1998; Larsen et al., 2009). Concomitantly, Relling and Reynolds (2008) observed decreased GLP-1 plasma concentration with abomasal starch infusion, which is in contrast to observations with nonruminants, where increased GIP secretion and starch in the distal small intestine has been found to stimulate GLP-1 secretion (Damholt et al., 1998; Holst, 2004).

The plasma concentrations of the specific gut glucagon peptide OXM did not seem to increase in response to abomasal glucose infusion. Abomasal starch infusion in dairy cows did not affect plasma OXM concentrations (Relling et al., 2010a). In humans, OXM is cosecreted with GLP-1 (Holst, 1997), and Benson and Reynolds (2001) observed an increase in both GLP-1 and gut glucagon in response to abomasal oil infusion. However, the extent to which GLP-1 and OXM are co-secreted in ruminants is uncertain as no correlation was observed between arterial concentrations of GLP1 and OXM in the present study (Table 3) or in the studies reported by Relling and Reynolds (2008) and Relling et al. (2010a). Taken together, the observations with ruminants on secretion of GIP, GLP-1, and

Table 2. Paired $t$-tests of venous-arterial plasma concentration differences for glucose-dependent insulinotropic polypeptide (GIP), glucagon-like peptide 1(7-36) amide (GLP-1), oxyntomodulin (OXM), and active ghrelin across splanchnic tissues in periparturient cows

\begin{tabular}{lrrrr}
\hline Item $^{1}$ & $\mathrm{n}$ & Mean & SEM & $P$-value \\
\hline GIP, $\mathrm{p} M$ & & & & \\
P-A & 24 & -0.6 & 2.1 & 0.78 \\
H-A & 18 & 3.7 & 2.1 & 0.10 \\
H-P & 18 & 2.0 & 3.2 & 0.54 \\
GLP-1, pM & & & & \\
P-A & 24 & 2.4 & 0.4 & $<0.01$ \\
H-A & 18 & 1.7 & 0.8 & 0.04 \\
H-P & 18 & -1.0 & 0.8 & 0.27 \\
OXM, pM & & & & \\
P-A & 23 & 3.0 & 3.6 & 0.41 \\
H-A & 17 & -0.1 & 5.6 & 0.99 \\
H-P & 17 & -0.2 & 6.5 & 0.98 \\
Ghrelin prefeeding, pM & & & & \\
P-A & 22 & -5.9 & 2.5 & 0.03 \\
H-A & 14 & -0.7 & 3.9 & 0.85 \\
H-P & 15 & 3.7 & 5.0 & 0.48 \\
Ghrelin postfeeding, pM & & & & \\
P-A & 22 & -2.3 & 2.6 & 0.39 \\
H-A & 16 & 0.6 & 2.1 & 0.78 \\
H-P & 17 & 6.7 & 5.2 & 0.21 \\
\hline P & & & &
\end{tabular}

${ }^{1} \mathrm{P}-\mathrm{A}=$ portal venous-arterial plasma concentration difference; $\mathrm{H}-\mathrm{A}$ $=$ hepatic venous-arterial plasma concentration difference; $\mathrm{H}-\mathrm{P}=$ hepatic venous-portal venous plasma concentration difference. 
Table 3. Pearson correlation analysis among DMI and arterial plasma concentrations of glucose, insulin, NEFA, BHBA, glucose-dependent insulinotropic polypeptide (GIP), glucagon-like peptide 1(7-36) amide (GLP-1), oxyntomodulin (OXM), and active ghrelin ${ }^{1}$

\begin{tabular}{lcrrrrrrr}
\hline & DMI & Glucose & Insulin & NEFA & BHBA & GIP & GLP-1 & OXM \\
\hline Glucose & $-0.60^{*}$ & & & & & & & \\
Insulin & -0.30 & 0.39 & & & & & & \\
NEFA & -0.11 & 0.17 & -0.28 & & & & & \\
BHBA & $0.53^{*}$ & -0.48 & -0.12 & 0.10 & & & & \\
GIP & 0.32 & 0.01 & 0.13 & -0.35 & -0.11 & & & \\
GLP-1 & $0.55^{*}$ & -0.17 & -0.02 & -0.37 & -0.02 & $0.87^{* *}$ & & \\
OXM & 0.12 & 0.08 & 0.12 & -0.03 & -0.14 & 0.29 & 0.28 & \\
Ghrelin prefeeding & -0.12 & 0.17 & -0.07 & -0.16 & 0.02 & -0.02 & -0.14 & 0.01 \\
Ghrelin postfeeding & -0.29 & 0.26 & 0.13 & -0.25 & -0.09 & 0.01 & -0.18 & 0.20 \\
\hline
\end{tabular}

${ }^{1}$ For DMI, glucose, insulin, NEFA, and BHBA, see Larsen and Kristensen (2009). Mean values across time within cow and sampling day were used in correlation analysis. Asterisks signify probability of correlation: ${ }^{* *} P$ $<0.0001 ;{ }^{*} P<0.01$.

OXM in response to abomasal infusion of glucose or starch suggest the existence of species differences in the stimulatory effect of carbohydrates on GIP, GLP-1, and OXM secretion. Ruminants are not adapted to digest substantial amounts of starch in the small intestine, which may be the reason for the general absence of substantial positive effects of abomasal starch or glucose infusions on plasma concentrations of gut peptides in ruminants. This is further supported by a similar lack of adaptive secretion of pancreatic $\alpha$-amylase in response to abomasal starch infusion in steers (Harmon, 1992; Walker and Harmon, 1995).

The secretion of ghrelin in dairy cows does not appear to be reduced by increased presence of carbohydrates in the abomasum, as neither abomasal infusion of starch (Relling et al., 2010a) nor glucose (present study) decreased ghrelin concentrations in circulating blood. This is in contrast to findings with rats duodenally infused with glucose (Williams et al., 2003; Overduin et al., 2005). However, the lack of response in ghrelin secretion with dairy cows may be related to the use of continuous infusion for several days compared with infusion for few a minutes in the rat studies. In grazing lactating dairy cows, Roche et al. (2007) reported that supplementation with a starch-rich concentrate decreased postfeeding ghrelin concentrations in circulating blood, which could indicate that the effect of fed carbohydrates on ghrelin secretion differs from the effect of continuously infused glucose or starch. Further, sampling $30 \mathrm{~min}$ pre- and postfeeding may be too infrequent to capture effects on ghrelin secretion due to pulsatile ghrelin secretion (Roche et al., 2008).

\section{Transition to Lactation}

The net PDV release of GLP-1 during the transition period (Figure 1) was similar to that measured at both 55 and 111 DIM by Benson and Reynolds (2001) with a control infusion in a study investigating effects of abomasal oil infusion. Furthermore, no net hepatic metabolism of GLP-1 was measurable in the transition period (present study) or later in the lactation period (Benson and Reynolds, 2001). Therefore, the liver does not appear to participate in the regulation of GLP-1 concentrations in circulating blood in cattle.

The concentrations of GIP and GLP-1 in circulating blood increased from prepartum to 29 DIM in a quadratic manner, indicating a limited change in concentrations from prepartum to 4 DIM. Relling and Reynolds (2007) reported a linear increase in concentrations of GIP and GLP-1 from $11 \mathrm{~d}$ prepartum to $19 \mathrm{~d}$ postpartum. Using multiple regression analysis, Relling and Reynolds (2007) observed the postpartum increases in concentrations of GIP and GLP-1 to be related to actual DIM and not to actual DMI. A similar distinction between the effects of DIM and DMI was not possible with the present data due to the use of fixed sampling days relative to parturition, and the positive correlation between DIM and DMI. Thus, the observed positive correlation between DMI and GLP-1 (Table 3) is confounded with DIM. The lack of interactions between treatment and DIM in the present study supports the conclusions of Relling and Reynolds (2007), as abomasal glucose infusion had a negative effect on DMI, but the increase in gut peptide concentrations after parturition did not appear to be affected by treatment.

Itoh et al. (2005) reported that ghrelin concentrations decreased from early lactation (approximately 30 DIM) to late lactation in primiparous Holstein cows. In the present study, circulating ghrelin concentrations decreased from prepartum to 4 DIM, followed by increasing concentrations through to 29 DIM. However, it is not possible to establish a ghrelin concentration profile during the lactation-gestation cycle from these 2 studies, as cows were in different parities and different assays were used. Further, Itoh et al. (2005) obtained 
the profile by grouping a set of cows relative to parturition and not by following a set of cows through the lactation period.

Plasma ghrelin concentrations were generally greater prefeeding than postfeeding, as previously observed in dairy cows (Hayashida et al., 2001; Bradford et al., 2008; Relling et al., 2010a) and in sheep (Sugino et al., 2002). The prefeeding ghrelin concentrations were in particular greater prepartum compared with postpartum, which probably is related to the use of restricted feeding prepartum and ad libitum feeding postpartum. Ad libitum feeding has been observed to reduce prefeeding ghrelin concentrations in both steers (Wertz-Lutz et al., 2008) and sheep (Sugino et al., 2002; Relling et al., 2010b) compared with restricted feeding. Despite the greater prefeeding ghrelin concentrations, the overall level of ghrelin concentration in circulating blood was reflected both pre- and postfeeding. In fed and fasted steers, Wertz-Lutz et al. (2006) reported that circulating ghrelin concentrations inversely reflected the glucogenic status. In contrast, the immediate postpartum decrease in glucose and insulin concentrations with control cows (Larsen and Kristensen, 2009) did not increase ghrelin concentrations in the present study; indeed, arterial ghrelin concentrations did not correlate with any of the measured indicators of glucogenic status (Table 3). As discussed previously for GIP and GLP-1, plasma ghrelin concentrations were not correlated to DMI, even though pre- and postfeeding arterial ghrelin concentrations increased from 4 to 29 DIM.

The lower DMI with glucose infusion might have been caused by an impairment of ruminal digesta outflow, as no blank infusion was conducted with control cows. However, a test experiment demonstrated that the infusion device as used did not have a negative effect on DMI (Larsen and Kristensen, 2009). One of our hypotheses was that increased GLP-1 secretion with abomasal glucose infusion contributed to the lower DMI observed with abomasal glucose infusion; however, neither arterial concentration nor net PDV release of GLP-1 were affected by glucose infusion. Instead, cows receiving abomasal glucose infusion did not experience the normal abrupt decrease in plasma concentrations of glucose and insulin at parturition (Larsen and Kristensen, 2009). These may be of great importance for the endocrine cascade triggering metabolic adaptations to lactation. This is further supported by data obtained with the hyperinsulinemic-euglycemic clamp technique in periparturient cows (Leury et al., 2003). When elevating insulin and maintaining glucose levels at $7 \mathrm{~d}$ postpartum, Leury et al. (2003) observed a reduction in DMI from 18.7 to $12.6 \mathrm{~kg} / \mathrm{d}$, which is very similar to the situation induced by abomasal glucose infusion in the present experiment. Overall, the postpartum increases in arterial plasma concentrations of the measured gut peptide hormones seemed to be more closely correlated to the progression of early lactation than to DMI or glucogenic status.

\section{Splanchnic Concentration Differences}

Inadequate mixing of blood from the mesenteric and gastroduodenal veins causing laminar flow in the portal vein could have affected the portal venous concentration of gut peptide hormones, resulting in difficulties in obtaining significant $\mathrm{P}-\mathrm{A}$ concentration differences. This would relate particularly to those secreted from the abomasum and upper duodenum into the gastroduodenal vein (Seal and Reynolds, 1993). However, the similarity among arterial, portal, and hepatic venous concentrations of OXM and GIP do not indicate that laminar blood flow occurred in the portal vein. Furthermore, the limited number of replications, the use of pooled samples, and other factors such as the ability of RIA to measure small concentration differences, may have contributed to our inability to measure significant venous-arterial concentration differences for gut peptides other than GLP-1. Positive P-A concentration differences would be expected for gut peptide hormones due to the secretion from gastro-intestinal tissues into venous blood. Thus, the generally negative $\mathrm{P}-\mathrm{A}$ concentration differences observed for ghrelin were unexpected, but may be related to the pulsatile nature of ghrelin secretion (Roche et al., 2008) in combination with only 2 sampling times around feeding.

\section{CONCLUSIONS}

Abomasal glucose infusion in postpartum transition dairy cows did not appear to affect arterial, portal venous, or hepatic venous plasma concentrations of the gut peptide hormones GLP-1, OXM, or GIP as expected based on effects of abomasal starch infusion reported for nonruminants. However, concentrations of these gut peptide hormones in circulating blood increased as lactation progressed. From these data, we conclude that changes in plasma concentrations of these gut peptide hormones do not appear to contribute to alterations in intake or glucose metabolism observed in postpartum transition cows receiving abomasal glucose infusions.

\section{ACKNOWLEDGMENTS}

Funding was provided by the Danish Cattle Federation (Aarhus, Denmark); Faculty of Agricultural Sciences, Aarhus University (Tjele, Denmark); the Ohio Agricultural Research and Development Center at The Ohio State University (Wooster), and the University of 
Reading (Reading, UK). M. Larsen was supported by an industrial $\mathrm{PhD}$ fellowship program under the Danish Ministry of Science, Technology, and Innovation (Copenhagen, Denmark).

\section{REFERENCES}

Benson, J. A., and C. K. Reynolds. 2001. Effects of abomasal infusion of long-chain fatty acids on splanchnic metabolism of pancreatic and gut hormones in lactating dairy cows. J. Dairy Sci. $84: 1488-1500$

Bradford, B. J., K. J. Harvatine, and M. S. Allen. 2008. Dietary unsaturated fatty acids increase plasma glucagon-like peptide-1 and cholecystokinin and may decrease premeal ghrelin in lactating dairy cows. J. Dairy Sci. 91:1443-1450.

Damholt, A. B., A. M. J. Buchan, and H. Kofod. 1998. Glucagon-likepeptide-1 secretion from canine L-cells is increased by glucosedependent-insulinotropic peptide but unaffected by glucose. Endocrinology 139:2085-2091.

Harmon, D. L. 1992. Dietary influences on carbohydrases and small intestinal starch hydrolysis capacity in ruminants. J. Nutr. $122: 203-210$

Harvey, R. B., and A. J. Brothers. 1962. Renal extraction of paraaminohippurate and creatine measured by continuous in vivo sampling of arterial and renal-vein blood. Ann. N. Y. Acad. Sci. 102:46-54.

Hayashida, T., K. Murakami, K. Mogi, M. Nishihara, M. Nakazato, M. S. Mondal, Y. Horii, M. Kojima, K. Kangawa, and N. Murakami. 2001. Ghrelin in domestic animals: Distribution in stomach and its possible role. Domest. Anim. Endocrinol. 21:17-24.

Holst, J. J. 1997. Enteroglucagon. Annu. Rev. Physiol. 59:257-271.

Holst, J. J. 2004. On the physiology of GIP and GLP-1. Horm. Metab. Res. 36:747-754.

Inui, A., A. Asakawa, C. Y. Bowers, G. Mantovani, A. Laviano, M. M. Meguid, and M. Fujimiya. 2004. Ghrelin, appetite, and gastric motility: The emerging role of the stomach as an endocrine organ. FASEB J. 18:439-456.

Itoh, F., T. Komatsu, M. Yonai, T. Sugino, M. Kojima, K. Kangawa, Y. Hasegawa, Y. Terashima, and K. Hodate. 2005. GH secretory responses to ghrelin and GHRH in growing and lactating dairy cattle. Domest. Anim. Endocrinol. 28:34-45.

Knapper, J. M. E., A. Heath, J. M. Fletcher, L. M. Morgan, and V. Marks. 1995. GIP and GLP-1(7-36)amide secretion in response to intraduodenal infusions of nutrients in pigs. Comp. Biochem. Physiol. C Pharmacol. Toxicol. Endocrinol. 111:445-450.

Knowlton, K. F., B. P. Glenn, and R. A. Erdman. 1998. Performance, ruminal fermentation, and site of starch digestion in early lactation cows fed corn grain harvested and processed differently. J. Dairy Sci. 81:1972-1984.

Kristensen, N. B., A. C. Storm, B. M. L. Raun, B. A. Røjen, and D. L. Harmon. 2007. Metabolism of silage alcohols in lactating dairy cows. J. Dairy Sci. 90:1364-1377.

Larsen, M., and N. B. Kristensen. 2009. Effect of abomasal glucose infusion on splanchnic and whole body glucose metabolism in periparturient dairy cows. J. Dairy Sci. 92:1071-1083.

Larsen, M., P. Lund, M. R. Weisbjerg, and T. Hvelplund. 2009. Digestion site of starch from cereals and legumes in lactating dairy cows. Anim. Feed Sci. Technol. 153:236-248.
Leury, B. J., L. H. Baumgard, S. S. Block, N. Segoale, R. A. Ehrhardt, R. P. Rhoads, D. E. Bauman, A. W. Bell, and Y. R. Boisclair. 2003. Effect of insulin and growth hormone on plasma leptin in periparturient dairy cows. Am. J. Physiol. Regul. Integr. Comp. Physiol. 285:R1107-R1115.

Løvendahl, P., and H. M. Purup. 2002. Technical note: Time-resolved fluoro-immunometric assay for intact insulin in livestock species. J. Anim. Sci. 80:191-195.

Overduin, J., R. S. Frayo, H. J. Grill, J. M. Kaplan, and D. E. Cummings. 2005. Role of the duodenum and macronutrient type in ghrelin regulation. Endocrinology 146:845-850.

Relling, A. E., S. C. Loerch, and C. K. Reynolds. 2010a. Plasma ghrelin and oxyntomodulin concentrations in lactating dairy cows receiving abomasal soybean oil, corn starch and casein infusions. Domest. Anim. Endocrinol. 38:284-288.

Relling, A. E., J. L. Pate, C. K. Reynolds, and S. C. Loerch. 2010b. Effect of feed restriction and supplemental dietary fat on gut peptide and hypothalamic neuropeptide mRNA concentrations in growing wethers. J. Anim. Sci. 88:737-748.

Relling, A. E., and C. K. Reynolds. 2007. Plasma concentrations of gut peptides in dairy cattle increase after calving. J. Dairy Sci. 90:325-330.

Relling, A. E., and C. K. Reynolds. 2008. Abomasal infusion of casein, starch and soybean oil differentially affect plasma concentrations of gut peptides and feed intake in lactating dairy cows. Domest. Anim. Endocrinol. 35:35-45.

Roche, J. R., D. Blache, J. K. Kay, D. R. Miller, A. J. Sheahan, and D. W. Miller. 2008. Neuroendocrine and physiological regulation of intake with particular reference to domesticated ruminant animals. Nutr. Res. Rev. 21:207-234.

Roche, J. R., A. J. Sheahan, L. M. Chagas, and D. P. Berry. 2007. Concentrate supplementation reduces postprandial plasma ghrelin in grazing dairy cows: A possible neuroendocrine basis for reduced pasture intake in supplemented cows. J. Dairy Sci. 90:13541363.

Seal, C. J., and C. K. Reynolds. 1993. Nutritional implications of gastrointestinal and liver metabolism in ruminants. Nutr. Res. Rev. 6:185-208.

Sugino, T., J. Yamaura, M. Yamagishi, A. Ogura, R. Hayashi, Y. Kurose, M. Kojima, K. Kangawa, Y. Hasegawa, and Y. Terashima. 2002. A transient surge of ghrelin secretion before feeding is modified by different feeding regimens in sheep. Biochem. Biophys. Res. Commun. 298:785-788.

Walker, J. A., and D. L. Harmon. 1995. Influence of ruminal or abomasal starch hydrolysate infusion on pancreatic exocrine secretion and blood glucose and insulin concentrations in steers. J. Anim. Sci. 73:3766-3774.

Wertz-Lutz, A. E., J. A. Daniel, J. A. Clapper, A. Trenkle, and D. C. Beitz. 2008. Prolonged, moderate nutrient restriction in beef cattle results in persistently elevated circulating ghrelin concentrations. J. Anim. Sci. 86:564-575.

Wertz-Lutz, A. E., T. J. Knight, R. H. Pritchard, J. A. Daniel, J. A. Clapper, A. J. Smart, A. Trenkle, and D. C. Beitz. 2006. Circulating ghrelin concentrations fluctuate relative to nutritional status and influence feeding behavior in cattle. J. Anim. Sci. 84:32853300 .

Williams, D. L., D. E. Cummings, H. J. Grill, and J. M. Kaplan. 2003. Meal-related ghrelin suppression requires postgastric feedback. Endocrinology 144:2765-2767. 